\title{
Perfis de Vulnerabilidade Feminina ao HIV/ aids em Belo Horizonte e Recife: comparando brancas e negras
}

\section{Profiles of Female Vulnerability to HIV/AIDS in Belo Horizonte and Recife: a comparison of white and black/mixed women}

\author{
Paula Miranda-Ribeiro \\ PhD em Sociologia. Professora Associada do Departamento de \\ Demografia e do Centro de Desenvolvimento e Planejamento \\ (Cedeplar) da Universidade Federal de Minas Gerais. \\ Endereço: UFMG/Faculdade de Ciências Econômicas/Cedeplar, Av. \\ Antônio Carlos 6627, CEP 30270-901, Belo Horizonte, MG, Brasil. \\ E-mail: paulaळcedeplar.ufmg.br

\section{Andréa Branco Simão} \\ Doutora em Demografia. Professora da Pontifícia Universidade \\ Católica de Minas Gerais e pesquisadora do Centro de Desenvol- \\ vimento e Planejamento Regional (Cedeplar) da Universidade \\ Federal de Minas Gerais. \\ Endereço: UFMG/Faculdade de Ciências Econômicas/Cedeplar, Av. \\ Antônio Carlos 6627, CEP 30270-90I, Belo Horizonte, MG, Brasil. \\ E-mail: deiaðcedeplar.ufmg.br
}

\section{André Junqueira Caetano}

PhD em Sociologia. Professor da Pontifícia Universidade Católica de Minas Gerais e pesquisador do Centro de Desenvolvimento e Planejamento Regional (Cedeplar) da Universidade Federal de Minas Gerais.

Endereço: UFMG/Faculdade de Ciências Econômicas/Cedeplar, Av. Antônio Carlos 6627, CEP 30270-901, Belo Horizonte, MG, Brasil.

E-mail: caetano@cedeplar.ufmg.br

Marisa Alves Lacerda

Doutora em Demografia.

Endereço: UFMG/Faculdade de Ciências Econômicas/Cedeplar, Av. Antônio Carlos 6627, CEP 30270-90I, Belo Horizonte, MG, Brasil.

E-mail: maralazळhotmail.com

\section{Maria Eponina de Abreu e Torres}

Mestre em Demografia. Professora de Sociologia no Colégio Loyola, Belo Horizonte.

Endereço: UFMG/Faculdade de Ciências Econômicas/Cedeplar, Av. Antônio Carlos 6627, CEP 30270-901, Belo Horizonte, MG, Brasil.

E-mail: falecomninaœgmail.com

\section{Resumo}

Objetivo: Delinear e comparar os perfis das mulheres brancas e negras entre 18 e 59 anos, residentes em Belo Horizonte e Recife, enfocando características sociodemográficas e de conhecimento, além de atitudes em relação ao HIV/aids. Métodos: Os dados são oriundos da pesquisa amostral SRSR - Saúde Reprodutiva, Sexualidade e Raça/Cor, conduzida pelo Cedeplar/UFMG em 2002 e única desta natureza com representatividade municipal. 0 método utilizado foi o Grade of Membership (GoM), a partir do qual foram gerados quatro perfis extremos para cada município. Resultados: Tanto em Belo Horizonte quanto em Recife, as mulheres com maior probabilidade de serem brancas são também aquelas com maior probabilidade de ter escolaridade mais elevada, possuir plano de saúde, ter tido parceiro estável no ano anterior à pesquisa e ter poder na relação sexual. Quanto às negras, apenas em Belo Horizonte elas têm maior probabilidade de serem de baixa escolaridade, não possuírem plano de saúde, além de se sentirem desempoderadas diante do parceiro sexual. Conclusões: A comparação dos perfis de brancas e negras em Belo Horizonte e Recife revela diferenças na vulnerabilidade dessas mulheres ao HIV/aids. As diferenças entre os dois grupos são mais evidentes em Belo Horizonte.

Palavras-chave: Aids; Relações raciais; Vulnerabilidade; Mulher; Belo Horizonte; Recife. 


\section{Abstract}

OBJECTIVE: To delineate and compare profiles of white and "Black" (either Black or mixed) women, 18 to 59 years-old, residents of Belo Horizonte and Recife (Brazil), focusing on their knowledge and attitudes about HIV/AIDS, as well as their sociodemographic characteristics. METHODS: Data come from the survey SRSR (Reproductive Health, Sexuality, and Race/Skin Color), conducted by Cedeplar in 2002 and the only one of its kind with representativeness at the municipality (county) level. Grade of Membership (GoM) was used to generate four profiles of women for each county. RESULTS: In Belo Horizonte and Recife, women who are more likely to be White are also more likely to have better education, health insurance, a stable partner in the year before the survey, and more power in their sexual partnership. Regarding the "Black" women in Belo Horizonte, they are more likely to have low education, no health insurance, and less power with their sexual partners. CONCLUSIONS: The comparison among the profiles of White and "Black" women in Belo Horizonte and Recife points to differences regarding their vulnerability to HIV/AIDS. The differences between the two racial groups are more evident in Belo Horizonte.

Keywords: AIDS; Race; Vulnerability; Woman; Belo Horizonte; Recife.

\section{Introdução}

Resultados de diversos estudos têm mostrado uma estreita correlação entre indicadores socioeconômicos desfavoráveis e o aumento da incidência do HIV/aids, doença que vem contagiando, em maior medida, indivíduos caracterizados por baixa escolaridade e nível de renda e residência em áreas geográficas com baixo índice de desenvolvimento humano. Além disso, a incidência da doença também vem mostrando um crescimento entre as mulheres e a população madura (50 a 59 anos) e idosa (6o anos e mais) (Barbosa, 2001; Bastos e Szwarcwald, 2000; Brasil, 2006, 2007; Diniz, [s.d.]; Fonseca e Bastos, 2007; Lopes, 2003; Villela, [200?]).

Os números do Ministério da Saúde revelam mudanças com relação à epidemia de aids, sobretudo nos últimos 15 anos. Entre os homens com 13 anos ou mais, a proporção dos casos de aids ${ }^{1}$ transmitidos por via heterossexual passou de 25,6\%, em 1996, para $42,6 \%$, em 2006, enquanto para as mulheres, essa via de transmissão foi responsável por 95,7\% e $86,1 \%$ dos casos, respectivamente. Já para os indivíduos com até 12 anos de idade, a transmissão vertical concentrava a maior parte dos casos ao longo do tempo - em 2006, a proporção era de 81,6\% (Brasil, 2007). Para os indivíduos acima de 50 anos, a razão de sexo dos casos de aids vem diminuindo drasticamente ao longo das décadas, tendo passado de 19 homens para cada mulher, em 1986, para 1,6 homens para cada mulher em 2006 (Brasil, 2007). Há, ainda, importantes variações regionais. Enquanto a taxa de incidência de casos de aids (por $100 \mathrm{mil}$ habitantes) em 2006 era de 12,7 em Minas Gerais, em Pernambuco esse valor era 15,4² (Brasil, 2007). No que tange à questão racial, embora haja limitações devido ao grande número de casos com essa informação ignorada, a razão entre brancos e negros vem diminuindo no que diz respeito à incidência, particularmente entre as mulheres, tendo passado de 16,1:1, em 2001, para 1,1:1, em 2006 (Brasil, 2007). Portanto, mais recentemente, mulheres brancas e negras têm se infectado na mesma proporção.

1 Notificados no Sistema de Informação de Agravos de Notificação (Sinan).

2 Casos de aids notificados no Sinan, declarados no SIM (Sistema de Informações sobre Mortalidade) e registrados no SISCEL/Siclom (Sistema de Controle de Exames Laboratoriais e Sistema de Controle Logístico de Medicamentos, respectivamente). 
Esse conjunto de mudanças na dinâmica da epidemia, com a infecção feminina tornando-se cada vez mais relevante, aponta a importância de entender melhor como fatores sociais, econômicos e demográficos, dentre eles o local de residência e a etnia/cor, se combinam para gerar diferentes níveis e tipos de vulnerabilidade para as mulheres. A questão das diferenças entre grupos raciais/de cor é particularmente importante, sobretudo para as mulheres, uma vez que estudos em diversas áreas, como saúde materno-infantil, mortalidade, emprego e renda, por exemplo, demonstram piores condições de vida para esse contingente populacional. Será que as negras também estão em condições menos favoráveis do que as brancas no se que diz respeito à vulnerabilidade ao HIV/aids?

O objetivo deste artigo é delinear e comparar os perfis das mulheres negras e brancas, entre 18 e 59 anos, residentes em Belo Horizonte e Recife, enfocando características sociodemográficas e de conhecimento e atitudes em relação ao HIV/aids. Os dados são oriundos da pesquisa amostral SRSR - Saúde Reprodutiva, Sexualidade e Raça/Cor, conduzida pelo Cedeplar/UFMG em 2002 e única dessa natureza com representatividade municipal. 0 método utilizado foi o Grade of Membership (GoM).

\section{Revisão de Literatura}

Diante da relação entre a dinâmica da epidemia e o contexto socioeconômico e cultural e das novas descobertas relativas ao HIV/aids, o conceito de risco torna-se cada vez menos adequado para explicar, de forma abrangente, a diversidade das dinâmicas e das interações possíveis entre o espaço geográfico e os grupos sociais de um lado e a epidemia de outro. Santos e Iriart (2007), por exemplo, apontam que a crença na existência de grupos de riscos, característica do início da epidemia de aids, pode ser encarada como um dos fatores que gerou baixa eficácia das ações preventivas entre as mulheres, já que elas não eram vistas como integrantes desses grupos.

As limitações no conceito de risco fortaleceram a noção de vulnerabilidade, que vem ganhando cada vez mais espaço nos estudos desenvolvidos sobre o HIV/aids. Mann e colaboradores (1992) operacio- nalizam a noção de vulnerabilidade a partir de três aspectos distintos, porém interdependentes. 0 primeiro refere-se à ideia de contexto social, entendido como o espaço em que são criadas, negociadas e modificadas as normas e valores que influenciam os comportamentos e as condutas sociais. O segundo, denominado programático, trata dos programas nacionais de combate à aids, da informação e da educação. Por fim, o terceiro aspecto aborda a questão do comportamento pessoal, entendida como fundamental na determinação da vulnerabilidade, uma vez que as decisões, embora influenciadas pelos demais aspectos, são tomadas em nível individual.

Outros estudos com o mesmo foco apontaram a necessidade de pôr fim à invisibilidade dos diferenciais culturais, socioeconômicos e de gênero como geradores de distintos níveis de vulnerabilidade ao HIV/aids e de sua percepção, identificando a existência de relação entre essas características e a percepção individual da vulnerabilidade ou do risco de infecção pelo HIV (Diniz ([s.d.]; Antunes e col., 2002; Paiva e col., 1998). Alguns estudos apontam para o fato de que a permanência da ideia de grupos de risco e a confiança no parceiro - implícita nos relacionamentos estáveis - afetam a percepção do risco pessoal, levando a comportamentos individuais de risco e, consequentemente, ao aumento da vulnerabilidade (Paiva e col., 1998). Outros sugerem que o aumento do nível de informação, embora necessário, não é suficiente para garantir mudanças nas práticas sexuais, alegando que, para além do nível de informação, é necessário considerar as diferenças nos modos de viver a sexualidade e nas normas e valores que determinam o processo de socialização sexual dos indivíduos (Santelli e col., 1996 Santelli e col., 1998; Antunes e col., 2002). Além disso, em muitos casos, o risco é apontado, em algumas pesquisas, como tendo uma dimensão de destino, parte do custo intrínseco de qualquer relação afetivo-sexual (Finkler e col., 2004). Estudo qualitativo em Belo Horizonte e Recife revelou, ainda, que a vulnerabilidade ao HIV/aids pode estar relacionada ao fato de as mulheres (e não apenas os homens) não gostarem de usar camisinha (Miranda-Ribeiro e col., 2009).

Diante do exposto, neste estudo, a vulnerabilidade ao HIV/aids será analisada como: 
[...] o reflexo da incapacidade de um indivíduo ou comunidade controlar seu risco de infecção ao HIV. Pobreza, desigualdade de gênero e deslocamentos em função de conflitos ou desastres naturais são exemplos de fatores econômicos ou sociais que podem ampliar a vulnerabilidade dos indivíduos ao HIV. Ambos, risco e vulnerabilidade, precisam ser focalizados no planejamento de respostas à epidemia (UNAIDS, 1998, apud Report on the Global AIDS Epidemic, Chapter 5, page 105, 2005).

Este conceito vem reafirmar a relação entre comportamento individual e contexto social e programático na definição dos níveis de vulnerabilidade e, consequentemente, no planejamento e consecução de estratégias para o enfrentamento dessa epidemia. Neste estudo, o foco está voltado para o aspecto do comportamento pessoal e na interação deste com o aspecto social.

Em relação às questões de raça, a população negra brasileira (que reúne os autodeclarados pardos e pretos, segundo as categorias do IBGE), sob diferentes aspectos, ainda se encontra em grande desvantagem quando comparada à população branca. São os negros que apresentam níveis de mortalidade infantil e materna e de desnutrição mais altos, níveis de escolaridade e de renda mais baixos e que têm os mais altos níveis de vitimização em termos de violência e criminalidade. É exatamente nas populações carentes, em que os negros se encontram sobrerepresentados, que as desigualdades de gênero são mais evidentes. Também é importante observar o fato de que o acesso à informação satisfatória ainda está vinculado, de forma bastante estreita, ao acesso à educação formal, a serviços de saúde e a meios de comunicação de maior resolutividade, os quais, por seu curso, dependem quase sempre de uma renda que permita custear esses bens. Boa parte da população negra possui acesso limitado não só à renda, mas também aos demais aspectos mencionados. Assim, é possível supor que as mulheres negras se encontrem mais fortemente expostas a condições de vida desfavoráveis, inclusive se comparadas à população negra masculina. Tudo isso implica em níveis mais altos de vulnerabilidade também ao HIV/aids (IBGE, 2002; Olinto e Olinto, 200o; Olinto e Galvão, 1999). Esse conjunto de fatores inter-relacionados reafirma a importância do olhar multifacetado sobre a questão da percepção de risco e da vulnerabilidade das mulheres nos dois municípios em questão, em especial do destaque dado aos diferenciais raciais nesta percepção e nos níveis diferenciais de vulnerabilidade que ela implica.

\section{Dados e Metodologia}

Os dados utilizados são oriundos da pesquisa amostral $^{3}$ Saúde Reprodutiva, Sexualidade e Raça/Cor - SRSR 4 , levada a campo pelo Cedeplar/UFMG, em 2002 em Belo Horizonte e Recife. No total, foram entrevistadas 2.408 mulheres entre 15 e 59 anos, sendo 1.301 em Belo Horizonte e 1.107 em Recife, representando, respectivamente, 875.476 e 525.406 mulheres desta faixa etária (Miranda-Ribeiro e col., 2004). Este artigo leva em consideração apenas as mulheres com idades entre 18 a 59 anos que se autodeclararam brancas, pardas ou pretas 5 . As mulheres que se declararam pardas ou pretas foram, para esta análise, agrupadas na categoria negra, que não só faz parte do sistema classificatório proposto pelo Movimento Negro (Telles, 2003), como também encontra suporte em estudos acadêmicos (Carvalho e col., 2004). Vale ressaltar que, seguindo a tradição dos grandes sociólogos brasileiros contemporâneos que pensam essa questão no país, raça está concebida como construção social e não tem qualquer conotação biológica (Guimarães, 2003; Silva, 1999). Os termos raça e cor, utilizados aqui, fazem parte da formulação da pergunta utilizada pelo IBGE, que inspirou parte do bloco sobre raça/cor do questionário SRSR.

Para a definição de perfis de vulnerabilidade ao HIV/aids, foi utilizada a técnica Grade of Membership (GoM). Essa técnica foi escolhida por permitir

\footnotetext{
3 Amostra conglomerada em três estágios: sorteio do setor censitário, do domicílio e da mulher (caso houvesse mais de uma mulher elegível no domicílio).

4 Respeitando os princípios éticos que regem os estudos que envolvem seres humanos, a pesquisa que subsidiou os resultados aqui apresentados foi submetida ao Comitê de Ética em Pesquisa da UFMG e aprovada por ele.

5 As mulheres de 15 a 17 anos e aquelas que se autodeclararam amarelas ou indígenas foram excluídas da análise.
} 
a análise de grupos muito heterogêneos e, ao mesmo tempo, delinear perfis homogêneos internamente (Manton e col., 1994). O GoM opera segundo a lógica dos conjuntos nebulosos, possibilitando que um mesmo elemento - no caso, uma mesma mulher - pertença, simultaneamente, a múltiplos conjuntos, segundo diferentes escores ou graus de pertinência. A associação entre as categorias das variáveis no modelo delineia dois ou mais perfis, chamados de perfis extremos. Um escore de o indica que a mulher não possui nenhuma das características do perfil $X$, enquanto um escore de 1 mostra que a mulher possui todas as características do perfil $X$. É possível, ainda, que haja mulheres que estejam equidistantes a todos os perfis extremos, sem características que as aproximem de nenhum deles (Manton e col., 1994; Sawyer e col., 2002).

Existem dois critérios para definição do número de perfis delineados: um de natureza teórica e outro de natureza técnica. Teoricamente, sabemos que as mulheres não podem ser definidas simplesmente como vulneráveis e não vulneráveis, o que sugere a inadequação de usar, por exemplo, somente dois perfis. Tecnicamente, definir poucos perfis significa que muitos indivíduos estarão alocados inadequadamente dentro de um único perfil, que terá muita heterogeneidade interna. No caso deste estudo, além dos aspectos teóricos e técnicos considerados, o tamanho da amostra também influenciou a escolha por quatro perfis. Se mais perfis fossem delineados, alguns poderiam conter um número muito pequeno de casos, viesando os perfis delineados.

Tem-se que a soma dos produtos para os K perfis de GoM e gerados para cada indivíduo é:

$$
\mathrm{P}\left(\mathrm{x}_{\mathrm{ijl}}=1\right)=\sum_{\mathrm{k}-\mathrm{l}}^{\mathrm{k}} \mathrm{g}_{\mathrm{ik}} \lambda_{\mathrm{kjl}}
$$

em que $\mathrm{g}_{\mathrm{ik}}$ indica o pertencimento (g) do indivíduo (i) ao perfil (k), $\lambda_{\mathrm{kjl}}$ refere-se à probabilidade de que um indivíduo tipo puro de um perfil tenha a probabilidade $(\lambda)$ de resposta (l) à variável (j), no perfil (k); e $\mathrm{g}_{\mathrm{ik}} \lambda_{\mathrm{kjl}}$ indica a probabilidade de um indivíduo possuir a resposta l-ésima para a questão j-ésima (Caetano e Machado, 2009) ${ }^{6}$.

\section{Resultados}

\section{Belo Horizonte}

A Tabela 1 indica que, em Belo Horizonte, o perfil extremo 1 contemplou mulheres com maior probabilidade, vis-à-vis ao observado para a população, de serem negras, unidas e com 2 filhos, de terem entre 25 e 34 anos de idade e 1 a 7 anos de estudo. Essas mulheres têm maior probabilidade de serem protestantes ou pentecostais e de frequentarem cerimônias religiosas mais de uma vez por semana. Não possuem plano de saúde e não trabalham ou, quando trabalham, não têm renda. Representam maior probabilidade de usarem pílula como método contraceptivo e terem tido apenas um parceiro sexual no último ano, fruto de relacionamento estável. No que tange às relações de gênero, estas mulheres têm maior chance de não evitar a relação sexual caso o parceiro se recuse a usar camisinha e de não conversar com o parceiro sobre contracepção, uma vez que há maior probabilidade de o método ser escolhido somente pela entrevistada ou somente por seu parceiro. Sobre o HIV/aids, as mulheres deste perfil apresentam uma grande probabilidade de afirmarem que a doença tem cura ou não saberem se tem cura, embora tenham feito o teste de HIV/aids e considerarem possuir um risco nulo ou moderado de infecção.

As mulheres residentes em Belo Horizonte e pertencentes ao perfil 2 apresentam maior probabilidade de terem até 7 anos de estudo, de serem mais velhas (40 anos ou mais), separadas, divorciadas ou viúvas e de terem 3 filhos ou mais. Têm maior probabilidade de serem pentecostais ou protestantes praticantes (mais de uma vez por semana) e de não trabalharem nem estudarem, ou de trabalharem sem auferir renda. Este perfil agrega mulheres com maior probabilidade de terem iniciado a vida sexual mais cedo e de não terem utilizado método contraceptivo na primeira relação. Também são elas que apresentam maior probabilidade de serem esterilizadas e de não terem tido nenhum parceiro nos últimos 12 meses. Em termos de relações de gênero, são mulheres com maior probabilidade de

6 Para exemplos recentes de uso do GoM em pesquisas na área de saúde e mais detalhes sobre a técnica, consultar Sawyer e col., 2002; Miranda-Ribeiro e col., 2007; Alves e col., 2008; Torres e col., 2008. Para um artigo sobre aids utilizando GoM, consultar Bonolo e col., 2008. 
não tentar parar a relação sexual a qualquer momento ou, caso tentassem parar, afirmam não ter conseguido. Com relação ao conhecimento sobre HIV/aids, apresentam maior probabilidade de serem tão mal informadas sobre a questão quanto as mulheres do perfil 1 e de não terem feito o teste de HIV ou não saberem responder se o fizeram. Estas mulheres apresentam maior probabilidade de se autoperceberem sem risco de infecção.

As mulheres agrupadas no perfil 3 apresentam maior probabilidade de terem mais de 8 anos de estudo, de serem solteiras, mais jovens (18 a 29 anos), sem filhos e sem religião ou outra religião que não a católica, a protestante ou a pentecostal. Apresentam, ainda, maior probabilidade de terem plano de saúde, de só estudarem ou de estudarem e trabalharem, de usarem preservativo, de terem tido mais de um parceiro nos últimos 12 meses e de estes parceiros terem sido ocasionais. Em termos de relações de gênero, estas mulheres apresentam maior probabilidade de dizer que evitariam a relação com alguma certeza, caso o parceiro se recusasse a usar camisinha. Apresentam, ainda, maior probabilidade de nunca terem feito um teste de HIV. Por fim, as mulheres deste perfil apresentaram maior probabilidade de se autoperceberem com um risco moderado de contrair a doença.

Por fim, as mulheres do perfil 4 apresentam maior probabilidade de serem brancas e casadas, terem entre 30 e 39 anos de idade, 8 ou mais anos de estudo e entre 1 e 2 filhos, trabalharem e não terem religião ou terem outras além de católica, protestante ou pentecostal. Apresentam, ainda, maior probabilidade de estarem usando preservativo, de terem tido apenas um parceiro nos últimos 12 meses e de este ser estável. Em termos de relações de gênero, provavelmente evitariam a relação com certeza se o parceiro se recusasse a usar camisinha e têm maior chance de que a decisão do uso de métodos contraceptivos seja do casal. Estas mulheres apresentam uma maior probabilidade de se autoperceberem com um risco pequeno em relação ao HIV/aids, de terem feito um teste desta doença há mais de um ano e de terem plano de saúde.

\section{Tabela I - Frequências marginais, probabilidades estimadas e fatores delineadores de perfis extremos, segundo variáveis selecionadas, para mulheres entre 18 a 59 anos de estudo. Belo Horizonte, 2002.}

\begin{tabular}{|c|c|c|c|c|c|c|c|c|c|c|c|}
\hline Variável & Categorias & $\mathrm{N}$ & $\mathrm{F}$ & $\mathrm{PI}$ & $\mathrm{P}_{2}$ & $P_{3}$ & $\mathrm{P}_{4}$ & $\mathrm{PI} / \mathrm{F}$ & $\mathrm{P}_{2} / \mathrm{F}$ & $P_{3} / F$ & $\mathrm{P}_{4} / \mathrm{F}$ \\
\hline \multirow{9}{*}{ vı grupo etário } & 0 "18 a $19 "$ & 39 & 3,6 & 0,00 & 0,00 & 0,18 & 0,00 & 0,00 & 0,00 & 5,11 & 0,00 \\
\hline & I "20 a $24 "$ & 142 & 12,9 & 0,14 & 0,00 & 0,55 & 0,00 & 1,12 & 0,00 & 4,25 & 0,00 \\
\hline & 2 "25 a $29 "$ & 167 & 15,2 & 0,45 & 0,00 & 0,27 & 0,00 & 2,95 & 0,00 & 1,77 & 0,00 \\
\hline & 3 "30 a $34 "$ & 173 & 15,8 & 0,27 & 0,00 & 0,00 & 0,36 & 1,70 & 0,00 & 0,00 & 2,31 \\
\hline & 4 "35 a $39 "$ & 158 & 14,4 & 0,05 & 0,00 & 0,00 & 0,49 & 0,36 & 0,00 & 0,00 & 3,43 \\
\hline & 5 "40 a $44 "$ & 134 & 12,2 & 0,09 & 0,20 & 0,00 & 0,14 & 0,71 & 1,66 & 0,00 & 1,16 \\
\hline & 6 "45 a $49 "$ & 126 & 11,5 & 0,00 & 0,34 & 0,00 & 0,00 & 0,00 & 3,00 & 0,00 & 0,00 \\
\hline & 7 "50 a $54 "$ & 84 & 7,7 & 0,00 & 0,24 & 0,00 & 0,00 & 0,00 & 3,10 & 0,00 & 0,00 \\
\hline & 8 "55 a $59 "$. & 75 & 6,8 & 0,00 & 0,21 & 0,00 & 0,00 & 0,00 & 3,16 & 0,00 & 0,00 \\
\hline \multirow{2}{*}{ v2 cor da pele } & o "branca" & 504 & 45,9 & 0,24 & 0,41 & 0,42 & 0,75 & 0,53 & 0,89 & 0,93 & 1,64 \\
\hline & I "negra". & 594 & 54,1 & 0,76 & 0,59 & 0,58 & 0,25 & 1,40 & 1,09 & 1,06 & 0,46 \\
\hline \multirow{5}{*}{ v3 situação conjugal } & o "nunca unida" & 230 & 20,9 & 0,00 & 0,00 & 1,00 & 0,00 & 0,00 & 0,00 & 4,78 & 0,00 \\
\hline & I "casada" & 512 & 46,6 & 0,40 & 0,40 & 0,00 & 1,00 & 0,85 & 0,87 & 0,00 & 2,15 \\
\hline & 2 "unida" & 187 & 17,0 & 0,60 & 0,00 & 0,00 & 0,00 & 3,54 & 0,00 & 0,00 & 0,00 \\
\hline & 3 "sep./div." & 129 & 11,7 & 0,00 & 0,47 & 0,00 & 0,00 & 0,00 & 3,98 & 0,00 & 0,00 \\
\hline & 4 "viúva". & 40 & 3,6 & 0,00 & 0,13 & 0,00 & 0,00 & 0,00 & 3,59 & 0,00 & 0,00 \\
\hline
\end{tabular}




\begin{tabular}{|c|c|c|c|c|c|c|c|c|c|c|c|}
\hline Variável & Categorias & $\mathrm{N}$ & $\mathrm{F}$ & $\mathrm{PI}$ & $\mathrm{P}_{2}$ & $P_{3}$ & $\mathrm{P}_{4}$ & $\mathrm{PI} / \mathrm{F}$ & $\mathrm{P}_{2} / \mathrm{F}$ & $P_{3} / F$ & $\mathrm{P}_{4} / \mathrm{F}$ \\
\hline \multirow{5}{*}{$\mathrm{V}_{4}$ escolaridade } & o "sem esc." & 26 & 2,4 & 0,00 & 0,08 & 0,00 & 0,00 & 0,00 & 3,45 & 0,00 & 0,00 \\
\hline & I "I a 3 anos" & 90 & 8,2 & 0,11 & 0,20 & 0,00 & 0,00 & 1,30 & 2,44 & 0,00 & 0,00 \\
\hline & 2 "4 a 7 anos" & 338 & 30,8 & 0,80 & 0,45 & 0,00 & 0,00 & 2,60 & 1,47 & 0,00 & 0,00 \\
\hline & 3 "8 a II anos" & 458 & 41,7 & 0,09 & 0,26 & 0,69 & 0,62 & 0,23 & 0,63 & 1,65 & 1,49 \\
\hline & 4 "12 anos ou mais". & 186 & 16,9 & 0,00 & 0,00 & 0,31 & 0,38 & 0,00 & 0,00 & 1,85 & 2,24 \\
\hline \multirow{4}{*}{ v5 religião } & o "nenhuma" & 95 & 8,7 & 0,00 & 0,00 & 0,18 & 0,20 & 0,00 & 0,00 & 2,02 & 2,32 \\
\hline & I "católica" & 667 & 60,7 & 0,50 & 0,64 & 0,62 & 0,68 & 0,83 & 1,05 & 1,02 & 1,12 \\
\hline & 2 "prot./pent." & 264 & 24,0 & 0,50 & 0,30 & 0,11 & 0,00 & 2,07 & 1,26 & 0,46 & 0,00 \\
\hline & 3 "outras". & 72 & 6,6 & 0,00 & 0,06 & 0,10 & 0,12 & 0,00 & 0,88 & 1,45 & $\mathrm{I}, 75$ \\
\hline \multirow{5}{*}{ v6 frequência religiosa } & o "não freq." & 171 & 15,6 & 0,08 & 0,05 & 0,26 & 0,26 & 0,53 & 0,32 & 1,68 & 1,67 \\
\hline & I "- de I vez p/ mês" & 152 & 13,8 & 0,13 & 0,07 & 0,15 & 0,22 & 0,97 & 0,47 & 1,10 & 1,56 \\
\hline & 2 "pelo menos de 15 em 15 " & 226 & 20,6 & 0,11 & 0,22 & 0,31 & 0,20 & 0,55 & 1,08 & 1,49 & 0,97 \\
\hline & 3 "uma vez por semana" & 327 & 29,8 & 0,31 & 0,33 & 0,20 & 0,32 & 1,04 & I,II & 0,69 & 1,09 \\
\hline & 4 "mais de uma vez por semana". & 222 & 20,2 & 0,36 & 0,33 & 0,07 & 0,00 & 1,79 & 1,65 & 0,36 & 0,00 \\
\hline \multirow{4}{*}{ v7 parturição } & 0. & 270 & 24,6 & 0,00 & 0,00 & 1,00 & 0,00 & 0,00 & 0,00 & 4,07 & 0,00 \\
\hline & I. & 240 & 21,9 & 0,21 & 0,00 & 0,00 & 0,70 & 0,94 & 0,00 & 0,00 & 3,18 \\
\hline & 2. & 268 & 24,4 & 0,54 & 0,16 & 0,00 & 0,30 & 2,23 & 0,66 & 0,00 & 1,24 \\
\hline & 3 e mais & 320 & 29,1 & 0,25 & 0,84 & 0,00 & 0,00 & 0,86 & 2,88 & 0,00 & 0,00 \\
\hline \multirow{2}{*}{$\begin{array}{l}\text { v8 possui plano } \\
\text { de saúde }\end{array}$} & o "sem plano" & 611 & 55,6 & 1,00 & 0,61 & 0,68 & 0,00 & 1,80 & 1,10 & 1,22 & 0,00 \\
\hline & I "com plano". & 487 & 44,4 & 0,00 & 0,39 & 0,32 & 1,00 & 0,00 & 0,87 & 0,73 & 2,25 \\
\hline \multirow{6}{*}{$\begin{array}{l}\text { v9 atividade } \\
\text { de trabalho } \\
\text { e estudo }\end{array}$} & o "só estuda" & 16 & 1,5 & 0,00 & 0,00 & 0,07 & 0,00 & 0,00 & 0,00 & 4,85 & 0,00 \\
\hline & I "est. e trab. c/ renda" & 89 & 8,1 & 0,00 & 0,00 & 0,34 & 0,03 & 0,00 & 0,00 & 4,23 & 0,40 \\
\hline & 2 "est. e trab. s/ renda" & 10 & 0,9 & 0,00 & 0,00 & 0,00 & 0,00 & 0,00 & 0,00 & 0,00 & 0,00 \\
\hline & 3 "só trab. c/ renda" & 605 & 55,1 & 0,31 & 0,50 & 0,53 & 0,94 & 0,56 & 0,90 & 0,95 & 1,70 \\
\hline & 4 "só trab. s/ renda" & 251 & 22,9 & 0,46 & 0,35 & 0,00 & 0,03 & 2,02 & 1,51 & 0,00 & 0,13 \\
\hline & 5 "não trab. nem est.". & 127 & 11,6 & 0,23 & 0,16 & 0,06 & 0,00 & 1,96 & 1,35 & 0,50 & 0,00 \\
\hline \multirow{6}{*}{ vıo primeiro método } & o "nunca usou método" & 28 & 2,6 & 0,00 & 0,06 & 0,04 & 0,00 & 0,00 & 2,26 & 1,61 & 0,00 \\
\hline & I "pílula" & 622 & 56,6 & 0,87 & 0,70 & 0,00 & 0,67 & 1,54 & 1,24 & 0,00 & 1,18 \\
\hline & 2 "camisinhas" & 240 & 21,9 & 0,00 & 0,00 & 0,96 & 0,00 & 0,00 & 0,00 & 4,38 & 0,00 \\
\hline & 3 "esterilização" & 30 & 2,7 & 0,00 & 0,09 & 0,00 & 0,00 & 0,00 & 3,49 & 0,00 & 0,00 \\
\hline & 4 "outros métodos" & 177 & 16,1 & 0,13 & 0,14 & 0,00 & 0,33 & 0,81 & 0,90 & 0,00 & 2,07 \\
\hline & 5 "não sabe/não respondeu". & 1 & 0,1 & 0,00 & 0,00 & 0,00 & 0,00 & 0,00 & 0,00 & 0,00 & 0,00 \\
\hline \multirow{5}{*}{$\begin{array}{l}\text { vil método usado } \\
\text { atualmente }\end{array}$} & o "não usa método" & 290 & 26,4 & 0,23 & 0,30 & 0,52 & 0,00 & 0,89 & 1,12 & 1,98 & 0,00 \\
\hline & I "pílula" & 217 & 19,8 & 0,48 & 0,00 & 0,24 & 0,23 & 2,44 & 0,00 & 1,22 & 1,16 \\
\hline & 2 "camisinhas" & 152 & 13,8 & 0,00 & 0,00 & 0,24 & 0,56 & 0,00 & 0,00 & 1,70 & 4,03 \\
\hline & 3 "esterilização" & 319 & 29,1 & 0,00 & 0,70 & 0,00 & 0,00 & 0,00 & 2,42 & 0,00 & 0,00 \\
\hline & 4 "outros métodos". & 120 & 10,9 & 0,28 & 0,00 & 0,00 & 0,22 & 2,60 & 0,00 & 0,00 & I,97 \\
\hline \multirow{6}{*}{$\begin{array}{l}\text { VI2 idade na primeira } \\
\text { relação }\end{array}$} & o "não informaram" & 12 & 1,1 & 0,00 & 0,00 & 0,05 & 0,00 & 0,00 & 0,00 & 4,99 & 0,00 \\
\hline & I "9 a $14 "$ & 60 & 5,5 & 0,14 & 0,06 & 0,01 & 0,00 & 2,54 & 1,02 & 0,26 & 0,00 \\
\hline & 2 "15 a $19 "$ & 551 & 50,2 & 0,76 & 0,44 & 0,82 & 0,09 & 1,52 & 0,88 & 1,63 & 0,17 \\
\hline & 3 " 20 a $24 "$ & 322 & 29,3 & 0,10 & 0,26 & 0,11 & 0,65 & 0,33 & 0,87 & 0,38 & 2,22 \\
\hline & 4 "25 a $29 "$ & 109 & 9,9 & 0,00 & 0,14 & 0,00 & 0,22 & 0,00 & 1,45 & 0,00 & 2,25 \\
\hline & 5 "30 e mais". & 44 & 4,0 & 0,00 & 0,10 & 0,00 & 0,04 & 0,00 & 2,55 & 0,00 & I,01 \\
\hline
\end{tabular}




\begin{tabular}{|c|c|c|c|c|c|c|c|c|c|c|c|}
\hline Vari & Categorias & $\mathrm{N}$ & $\mathrm{F}$ & $\mathrm{PI}$ & $\mathrm{P} 2$ & $P_{3}$ & $\mathrm{P}_{4}$ & $\mathrm{PI} / \mathrm{F}$ & $\mathrm{P}_{2} / \mathrm{F}$ & $P_{3} / F$ & $\mathrm{P}_{4} / \mathrm{F}$ \\
\hline \multirow{4}{*}{$\begin{array}{l}\text { VI3 método usado } \\
\text { na primeira relação } \\
\text { sexual }\end{array}$} & o "nenhum" & 594 & 54,1 & 1,00 & 1,00 & 0,10 & 0,00 & 1,85 & 1,85 & 0,19 & 0,00 \\
\hline & I "camisinha masculina" & 194 & 17,7 & 0,00 & 0,00 & 0,85 & 0,00 & 0,00 & 0,00 & 4,81 & 0,00 \\
\hline & 2 "outros métodos" & 300 & 27,3 & 0,00 & 0,00 & 0,00 & 1,00 & 0,00 & 0,00 & 0,00 & 3,66 \\
\hline & 3 "não sabe/não respondeu". & 10 & 0,9 & 0,00 & 0,00 & 0,05 & 0,00 & 0,00 & 0,00 & 5,06 & 0,00 \\
\hline \multirow{6}{*}{$\begin{array}{l}\text { VI4 média de } \\
\text { relações sexuais } \\
\text { por mês }\end{array}$} & o "o vezes" & 254 & 23,1 & 0,00 & 0,65 & 0,40 & 0,00 & 0,00 & $2,8 \mathrm{I}$ & 1,74 & 0,00 \\
\hline & I "I a 4 vezes" & 295 & 26,9 & 0,25 & 0,31 & 0,36 & 0,18 & 0,93 & 1,16 & 1,34 & 0,67 \\
\hline & 2 "5 a 8 vezes" & 200 & 18,2 & 0,26 & 0,00 & 0,00 & 0,38 & 1,41 & 0,00 & 0,00 & 2,07 \\
\hline & 3 "9 a 12 vezes" & 173 & 15,8 & 0,26 & 0,00 & 0,08 & 0,25 & 1,62 & 0,00 & 0,52 & 1,57 \\
\hline & 4 "13 e mais vezes" & 139 & 12,7 & 0,23 & 0,00 & 0,07 & 0,18 & 1,80 & 0,00 & 0,57 & 1,39 \\
\hline & 5 "não sabe/não respondeu". & 37 & 3,4 & 0,01 & 0,04 & 0,09 & 0,02 & 0,24 & 1,17 & 2,51 & 0,51 \\
\hline \multirow{4}{*}{$\begin{array}{l}\text { VI5 número de } \\
\text { parceiros sexuais } \\
\text { dos últimos } 12 \\
\text { meses }\end{array}$} & o "nenhum" & 147 & 13,4 & 0,00 & 0,50 & 0,00 & 0,00 & 0,00 & 3,71 & 0,00 & 0,00 \\
\hline & । "um" & 880 & 80,1 & 1,00 & 0,50 & 0,67 & 1,00 & 1,25 & 0,63 & 0,83 & 1,25 \\
\hline & 2 "dois ou mais" & 62 & 5,6 & 0,00 & 0,00 & 0,29 & 0,00 & 0,00 & 0,00 & 5,19 & 0,00 \\
\hline & 3 "não sabe/não respondeu". & 9 & 0,8 & 0,00 & 0,00 & 0,04 & 0,00 & 0,00 & 0,00 & 5,15 & 0,00 \\
\hline \multirow{4}{*}{$\begin{array}{l}\text { vi6 tipo de relação } \\
\text { com o último } \\
\text { parceiro sexual dos } \\
\text { últimos } 12 \text { meses }\end{array}$} & o "não teve sexo nos últ. 12 meses" & 156 & 14,2 & 0,00 & 0,52 & 0,00 & 0,00 & 0,00 & 3,66 & 0,00 & 0,00 \\
\hline & I "parceiro estável" & 895 & 81,5 & 1,00 & 0,42 & 0,88 & 1,00 & 1,23 & 0,51 & $\mathrm{I}, 07$ & 1,23 \\
\hline & 2 "parceiro ocasional" & 44 & 4,0 & 0,00 & 0,06 & 0,12 & 0,00 & 0,00 & 1,44 & 2,96 & 0,00 \\
\hline & 3 "não sabe/não respondeu". & 3 & 0,3 & 0,00 & 0,00 & 0,01 & 0,00 & 0,00 & 1,33 & 2,23 & 0,00 \\
\hline \multirow{5}{*}{$\begin{array}{l}\text { vı7 poder para parar } \\
\text { relação sexual com } \\
\text { último parceiro } \\
\text { sexual }\end{array}$} & o "Não tentaria evitar" & 106 & 9,7 & 0,24 & 0,12 & 0,00 & 0,00 & 2,51 & 1,27 & 0,00 & 0,00 \\
\hline & I "Tentaria, mas não conseg. evitar" & 59 & 5,4 & 0,10 & 0,07 & 0,04 & 0,00 & 1,78 & 1,34 & 0,79 & 0,00 \\
\hline & 2 "Com alg. certeza conseg. evitar" & 98 & 8,9 & 0,09 & 0,08 & 0,07 & 0,12 & 0,98 & 0,84 & 0,79 & 1,37 \\
\hline & 3 "Com certeza conseguiria evitar" & 826 & 75,2 & 0,57 & 0,73 & 0,85 & 0,88 & 0,76 & 0,97 & 1,13 & 1,17 \\
\hline & 4 "não sabe/não respondeu". & 9 & 0,8 & 0,00 & 0,00 & 0,04 & 0,00 & 0,00 & 0,00 & 5,14 & 0,00 \\
\hline \multirow{5}{*}{$\begin{array}{l}\text { vi8 poder de } \\
\text { evitar relação caso } \\
\text { parceiro não queira } \\
\text { usar condom }\end{array}$} & o "Não tentaria evitar" & 211 & 19,2 & 0,56 & 0,16 & 0,00 & 0,00 & 2,89 & 0,85 & 0,00 & 0,00 \\
\hline & I "Com alg. certeza conseg. evitar" & 128 & $\mathrm{II}, 7$ & 0,09 & 0,08 & 0,18 & 0,13 & 0,75 & 0,71 & 1,57 & 1,13 \\
\hline & 2 "Com certeza conseguiria evitar" & 741 & 67,5 & 0,36 & 0,73 & 0,79 & 0,87 & 0,53 & ।,08 & 1,16 & 1,29 \\
\hline & 3 "HSM" & 3 & 0,3 & 0,00 & 0,00 & 0,00 & 0,00 & 0,00 & 0,00 & 0,00 & 0,00 \\
\hline & 4 "Não sabe/não respondeu". & 15 & 1,4 & 0,00 & 0,03 & 0,03 & 0,00 & 0,00 & 1,79 & 2,26 & 0,00 \\
\hline \multirow{3}{*}{$\begin{array}{l}\text { VI9 se teve ou não } \\
\text { IST ou sintoma }\end{array}$} & o "não teve nos últ. 12 meses" & 701 & 63,8 & 0,35 & 0,82 & 0,57 & 0,79 & 0,55 & 1,29 & 0,89 & 1,24 \\
\hline & I "teve, não fez tratamento" & 141 & 12,8 & 0,25 & 0,09 & 0,18 & 0,00 & 1,94 & 0,74 & 1,42 & 0,00 \\
\hline & 2 "teve, procurou tratamento e fez". & 256 & 23,3 & 0,40 & 0,08 & 0,25 & 0,21 & $\mathrm{I}, 73$ & 0,36 & 1,08 & 0,91 \\
\hline \multirow{3}{*}{ v2o aids tem cura? } & o "não tem" & 1004 & 91,4 & 0,88 & 0,82 & 0,99 & 1,00 & 0,96 & 0,89 & 1,09 & 1,09 \\
\hline & I "tem" & 53 & 4,8 & 0,06 & 0,11 & 0,00 & 0,00 & 1,33 & 2,29 & 0,00 & 0,00 \\
\hline & 2 "não sabe/não respondeu". & 41 & 3,7 & 0,06 & 0,07 & 0,01 & 0,00 & 1,54 & 1,98 & 0,20 & 0,00 \\
\hline \multirow{5}{*}{$\begin{array}{l}\text { v2। autopercepção } \\
\text { de risco }\end{array}$} & o "não corre risco" & 431 & 39,3 & 0,65 & 0,59 & 0,33 & 00 & 1,65 & 1,51 & 0,83 & 0,00 \\
\hline & I "risco pequeno" & 420 & 38,3 & 0,00 & 0,21 & 0,41 & 0,88 & 0,00 & 0,55 & I,06 & 2,29 \\
\hline & 2 "risco moderado" & 169 & 15,4 & 0,28 & 0,10 & 0,20 & 0,08 & 1,81 & 0,65 & I,31 & 0,52 \\
\hline & 3 "risco grande" & 71 & 6,5 & 0,07 & 0,07 & 0,07 & 0,04 & 1,14 & 1,15 & 1,02 & 0,67 \\
\hline & 4 "não sabe/não respondeu". & 7 & 0,6 & 0,00 & 0,02 & 0,00 & 0,00 & 0,00 & 3,62 & 0,00 & 0,00 \\
\hline \multirow{4}{*}{$\begin{array}{l}\text { v22 se fez exame } \\
\text { de HIV quando fez }\end{array}$} & o "nunca fez" & 662 & 60,3 & 0,63 & 0,93 & 0,73 & 0,13 & 1,05 & 1,54 & 1,21 & 0,22 \\
\hline & I "fez há menos de I ano" & 142 & 12,9 & 0,23 & 0,00 & 0,27 & 0,07 & 1,76 & 0,00 & 2,10 & 0,57 \\
\hline & 2 "fez há mais de I ano" & 290 & 26,4 & 0,14 & 0,06 & 0,00 & 0,79 & 0,53 & 0,22 & 0,00 & 3,00 \\
\hline & 3 "não sabe/não respondeu". & 4 & 0,4 & 0,00 & 0,01 & 0,00 & 0,00 & 0,00 & 3,10 & 0,00 & 0,00 \\
\hline
\end{tabular}




\begin{tabular}{|c|c|c|c|c|c|c|c|c|c|c|c|}
\hline Variável & Categorias & $\mathrm{N}$ & $\mathrm{F}$ & $\mathrm{PI}$ & $\mathrm{P}_{2}$ & $P_{3}$ & $\mathrm{P}_{4}$ & $\mathrm{PI} / \mathrm{F}$ & $\mathrm{P} 2 / \mathrm{F}$ & $P_{3} / F$ & $\mathrm{P}_{4} / \mathrm{F}$ \\
\hline \multirow{5}{*}{$\begin{array}{l}\text { V24 teste de HIV em } \\
\text { pré-natal } \\
\text { (nascimentos até } \\
5 \text { anos antes da } \\
\text { pesquisa) }\end{array}$} & I "filho nos últ. 5 anos s/ teste" & 179 & 6,3 & 55 &, 00 & 0,00 &, 10 & 3,39 &, 00 &,$\infty 0$ & 0,61 \\
\hline & 2 "filho nos últ. 5 anos c/ teste" & 103 & 9,4 &,$\infty$ & 0,00 & 0,00 & 0,44 & 0,00 &, 00 & 0,00 & 4,73 \\
\hline & 3 "nunca teve filho" & 258 & 23,5 & 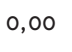 & 0,00 & 0,95 & 0,00 &,$\infty$ & 0,00 & 4,03 & 0,00 \\
\hline & 4 "grávida pela primeira vez" & 12 & 1,1 & 0,00 & 0,00 & 0,05 & 0,00 & 0,00 &,$\infty 0$ & 4,91 & 0,00 \\
\hline & 5 "teve filho há mais de 5 anos". & 546 & 49,7 & 0,45 & 1,00 & 0,00 & 0,46 & 0,90 & 2,01 & 0,00 & 0,92 \\
\hline \multirow{5}{*}{$\begin{array}{l}\text { V23 participação } \\
\text { do parceiro sobre a } \\
\text { decisão do uso do } \\
\text { método }\end{array}$} & o "só entrevistada" & 163 & 14,8 & 0,60 &, 00 & 0,00 & 0,00 & 4,05 & 0,00 & 0,00 & 0,00 \\
\hline & I "só o marido ou comp." & 19 & I,7 & 0,05 & 0,00 & 0,02 & 0,00 & 3,00 & 0,00 & I,35 & 0,00 \\
\hline & 2 "por ambos" & 398 & 36,2 & 0,30 & 0,00 & 0,41 & 1,00 & 0,82 & 0,00 & 1,13 & 2,76 \\
\hline & 3 "esterilizadas/sem parceiro fixo" & 485 & 44,2 & 0,00 & 0,94 & 0,57 & 0,00 & 0,00 & 2,13 & 1,29 & 0,00 \\
\hline & 4 "não sabe/não respondeu". & 33 & 3,0 & 0,05 & 0,06 & 0,00 & 0,00 & 1,70 & 1,94 & 0,00 & 0,00 \\
\hline
\end{tabular}

Fonte dos dados básicos: Pesquisa Saúde Reprodutiva, Sexualidade e Raça, 2002.

\section{Recife}

A Tabela 2 indica que, no caso de Recife, o perfil extremo 1 agrega mulheres com maior probabilidade de terem idades entre 25 e 34 anos e entre 40 a 54 anos, de serem unidas e com pelo menos três filhos, e de terem baixa escolaridade. Estas mulheres têm maior probabilidade de não terem religião alguma - embora a frequência marginal demonstre que a maioria delas é de religião católica - não trabalharem nem estudarem ou de exercerem alguma atividade remunerada e não estudarem. São mulheres com maior chance de serem esterilizadas e que, por isso, não utilizam preservativo atualmente nem o usaram na última relação sexual. São, ainda, mulheres com maior probabilidade de terem iniciado a vida sexual bastante jovens e de não terem usado método algum na primeira relação sexual. Quanto à vida sexual atual, trata-se de mulheres que têm maior probabilidade de terem tido apenas um parceiro sexual no último ano, mais provavelmente um parceiro estável, e de terem uma baixa frequência sexual. Estas mulheres possuem maior probabilidade, vis-à-vis à população total, de estarem em relações desiguais de gênero, não terem feito o teste de HIV no último ano e, embora tenham tido algum sintoma ou IST, ele não foi tratado.

No perfil extremo 2, as mulheres residentes em Recife possuem maior probabilidade de serem jovens (18 a 29 anos), solteiras ou unidas e com no máximo um filho, terem maior nível de escolaridade (pelo menos 8 anos de estudo), de só estudarem ou estudarem e trabalharem. São mulheres que, com maior probabilidade, usavam algum método que não a esterilização e que também usaram método na primeira relação sexual (que não a pílula), tendo essa primeira relação entre os 15 e 19 anos. Estas mulheres, com maior probabilidade, têm uma frequência sexual maior que as mulheres do perfil 1 (pelo menos 5 relações sexuais por mês) e tiveram dois ou mais parceiros sexuais no último ano, embora a última relação tenha sido com um parceiro estável. São mulheres que possuem maior poder na negociação sexual e que tiveram alguma IST ou sintoma no último ano, tendo sido tratado. Quanto ao risco de contrair o HIV, há uma maior probabilidade de ele ser percebido como pequeno ou moderado. A probabilidade de já terem feito o teste HIV é maior que o da população observada.

As mulheres de Recife que integram o perfil 3 têm maior probabilidade de serem mais velhas (acima de 40 anos), separadas e viúvas e com baixa escolaridade (até 3 anos de estudo). Em termos de parturição, as probabilidades apresentadas para este perfil são mais heterogêneas - 1 filho ou 3 filhos e mais. Adicionalmente, neste perfil, encontram-se as mulheres com maior probabilidade de terem tido a primeira relação sexual mais velhas (a partir dos 25 anos) e de não terem utilizado nenhum método nesta primeira relação. Neste perfil também estão as mulheres com maior probabilidade de não utilizarem métodos contraceptivos atualmente e que não tiveram (ou não souberam informar) nenhuma relação sexual nos 12 meses que antecederam a pesquisa. A probabilidade de não ter parceiro, ou de ter dois 
ou mais parceiros, é mais elevada para as mulheres deste perfil - a probabilidade mais elevada é de as mulheres terem um parceiro ocasional. Em termos de vulnerabilidade, as mulheres que integram o perfil 3 têm maior probabilidade de acreditarem que possuem algum risco de contrair HIV, de nunca terem realizado teste para HIV e de não saberem se o vírus tem cura.

As mulheres que integram o perfil 4 têm maior probabilidade de serem mulheres de 35 a 49 anos, brancas, casadas e com escolaridade mais elevada (acima de 8 anos de estudo). Quanto à religião, apresentam probabilidade mais elevada de serem protestantes ou pentecostais ou de pertencerem a outras religiões. Em termos de parturição, a maior probabilidade é de que essas mulheres tenham 2 filhos.
Neste perfil, encontram-se as mulheres com maior probabilidade de terem tido a primeira relação sexual quando tinham entre 20 e 29 anos e de terem utilizado algum método que não a camisinha masculina. Neste perfil também estão as mulheres com maior probabilidade de serem esterilizadas ou de terem parceiros vasectomizados, de não estarem utilizando nenhum método contraceptivo, de terem um parceiro estável e de terem uma média de 5 a 12 relações sexuais por mês. Em termos de vulnerabilidade, as mulheres que integram o perfil 4 têm maior probabilidade de acreditarem que possuem algum risco de contrair HIV e de não terem informado se realizaram teste para HIV. Por fim, a probabilidade de terem tido IST ou sintoma e de ter tido tratamento é mais elevada para as mulheres que integram este perfil.

Tabela 2 - Frequências marginais, probabilidades estimadas e fatores delineadores de perfis extremos, segundo variáveis selecionadas, para mulheres entre 18 a 59 anos de estudo. Recife, 2002.

\begin{tabular}{|c|c|c|c|c|c|c|c|c|c|c|c|}
\hline Variável & Categorias & $\mathrm{N}$ & $\mathrm{F}$ & $\mathrm{PI}$ & $\mathrm{P}_{2}$ & $P_{3}$ & $\mathrm{P}_{4}$ & $\mathrm{PI} / \mathrm{F}$ & $\mathrm{P}_{2} / \mathrm{F}$ & $P_{3} / F$ & $\mathrm{P}_{4} / \mathrm{F}$ \\
\hline \multirow{9}{*}{ vi grupo etário } & 0 "18 a $19 "$ & 33 & 3,7 & 0,00 & 0,12 & 0,00 & 0,00 & 0,00 & 3,16 & 0,00 & 0,00 \\
\hline & I "20 a $24 "$ & 104 & 11,5 & 0,00 & 0,35 & 0,00 & 0,00 & 0,00 & 3,05 & 0,00 & 0,00 \\
\hline & 2 "25 a $29 "$ & 152 & 16,9 & 0,23 & 0,36 & 0,00 & 0,00 & 1,37 & 2,15 & 0,00 & 0,00 \\
\hline & 3 "30 a $34 "$ & 145 & 16,1 & 0,27 & 0,17 & 0,07 & 0,14 & 1,67 & 1,05 & 0,46 & 0,88 \\
\hline & 4 "35 a $39 "$ & 143 & 15,9 & 0,00 & 0,00 & 0,00 & 0,54 & 0,00 & 0,00 & 0,00 & 3,42 \\
\hline & 5 " 40 a $44 "$ & 99 & 11,0 & 0,19 & 0,00 & 0,13 & 0,16 & 1,76 & 0,00 & $|, 2|$ & 1,47 \\
\hline & 6 " 45 a $49 "$ & 97 & 10,8 & 0,21 & 0,00 & 0,11 & 0,15 & 1,96 & 0,00 & 1,04 & 1,42 \\
\hline & 7 "50 a $54 "$ & 66 & 7,3 & 0,09 & 0,00 & 0,28 & 0,00 & 1,29 & 0,00 & 3,87 & 0,00 \\
\hline & 8 "55 a 59". & 63 & 7,0 & 0,00 & 0,00 & 0,40 & 0,00 & 0,00 & 0,00 & 5,67 & 0,00 \\
\hline \multirow{2}{*}{ v2 cor da pele } & o "branca" & 356 & 39,5 & 0,30 & 0,40 & 0,39 & 0,48 & 0,77 & 1,02 & 0,98 & 1,22 \\
\hline & I "negra". & 546 & 60,5 & 0,70 & 0,60 & 0,61 & 0,52 & 1,15 & 0,99 & I, OI & 0,86 \\
\hline \multirow{5}{*}{ v3 situação conjugal } & o "nunca unida" & 90 & 10,0 & 0,00 & 0,34 & 0,07 & 0,00 & 0,00 & 3,41 & 0,68 & 0,00 \\
\hline & I "casada" & 297 & 32,9 & 0,00 & 0,12 & 0,00 & 1,00 & 0,00 & 0,38 & 0,00 & 3,04 \\
\hline & 2 "unida" & 298 & 33,0 & 1,00 & 0,53 & 0,00 & 0,00 & 3,03 & 1,62 & 0,00 & 0,00 \\
\hline & 3 "sep./div." & 178 & 19,7 & 0,00 & 0,00 & 0,73 & 0,00 & 0,00 & 0,00 & 3,70 & 0,00 \\
\hline & 4 "viúva". & 39 & 4,3 & 0,00 & 0,00 & 0,20 & 0,00 & 0,00 & 0,00 & 4,70 & 0,00 \\
\hline \multirow{5}{*}{$\mathrm{V}_{4}$ escolaridade } & o "sem esc." & 54 & 6,0 & 0,11 & 0,00 & 0,18 & 0,00 & 1,78 & 0,00 & 2,95 & 0,00 \\
\hline & I "I a 3 anos" & 110 & 12,2 & 0,30 & 0,00 & 0,22 & 0,00 & 2,42 & 0,00 & 1,78 & 0,00 \\
\hline & 2 "4 a 7 anos" & 297 & 32,9 & 0,60 & 0,26 & 0,37 & 0,00 & 1,82 & 0,80 & 1,14 & 0,00 \\
\hline & 3 "8 a II anos" & 324 & 35,9 & 0,00 & 0,55 & 0,13 & 0,78 & 0,00 & 1,53 & 0,36 & 2,16 \\
\hline & 4 "12 anos ou mais". & 117 & 13,0 & 0,00 & 0,19 & 0,10 & 0,22 & 0,00 & 1,44 & 0,78 & 1,72 \\
\hline \multirow{4}{*}{ v5 religião } & o "nenhuma" & 108 & 12,0 & 0,18 & 0,24 & 0,00 & 0,00 & 1,50 & 2,02 & 0,00 & 0,00 \\
\hline & I "católica" & 512 & 56,8 & 0,63 & 0,53 & 0,67 & 0,48 & 1,12 & 0,92 & 1,19 & 0,84 \\
\hline & 2 "prot./pent." & 223 & 24,7 & 0,19 & 0,17 & 0,26 & 0,39 & 0,75 & 0,68 & 1,07 & 1,57 \\
\hline & 3 "outras". & 59 & 6,5 & 0,00 & 0,06 & 0,06 & 0,13 & 0,00 & 0,98 & 0,95 & 2,08 \\
\hline
\end{tabular}




\begin{tabular}{|c|c|c|c|c|c|c|c|c|c|c|c|}
\hline Variável & Categorias & $\mathrm{N}$ & $\mathrm{F}$ & $\mathrm{Pl}$ & $\mathrm{P} 2$ & $P_{3}$ & $\mathrm{P}_{4}$ & $\mathrm{PI} / \mathrm{F}$ & $\mathrm{P} 2 / \mathrm{F}$ & $\mathrm{P}_{3} / \mathrm{F}$ & $\mathrm{P}_{4} / \mathrm{F}$ \\
\hline \multirow{5}{*}{ v6 frequência religiosa } & o "nao freq." & 256 & 28,4 & 0,38 & 0,42 & 0,31 & 0,03 & 1,34 & 1,47 & 1,08 & 0,11 \\
\hline & I "- de I vez p/ mês" & 142 & 15,7 & 0,29 & 0,22 & 0,07 & 0,01 & ।,88 & 1,38 & 0,45 & 0,08 \\
\hline & 2 "pelo menos de 15 em 15 " & 167 & 18,5 & 0,12 & 0,20 & 0,15 & 0,25 & 0,64 & 1,09 & 0,83 & 1,37 \\
\hline & 3 "uma vez por semana" & 161 & 17,8 & 0,00 & 0,16 & 0,21 & 0,34 & 0,00 & 0,92 & 1,17 & 1,92 \\
\hline & 4 "mais de uma vez por semana". & 176 & 19,5 & 0,21 & 0,00 & 0,26 & 0,36 & 1,06 & 0,00 & 1,34 & 1,85 \\
\hline \multirow{4}{*}{ v7 parturição } & 0. & 174 & 19,3 & 0,00 & 0,51 & 0,16 & 0,00 & 0,00 & 2,63 & 0,81 & 0,00 \\
\hline & I. & 191 & 21,2 & 0,00 & 0,45 & 0,39 & 0,00 & 0,00 & 2,13 & 1,82 & 0,00 \\
\hline & 2. & 236 & 26,2 & 0,21 & 0,04 & 0,05 & 0,76 & 0,79 & 0,16 & 0,20 & 2,91 \\
\hline & 3 e mais & 301 & 33,4 & 0,79 & 0,00 & 0,41 & 0,24 & 2,37 & 0,00 & $\mathrm{I}, 2 \mathrm{l}$ & 0,71 \\
\hline \multirow{2}{*}{$\begin{array}{l}\text { v8 possui plano } \\
\text { de saúde }\end{array}$} & o "sem plano" & 619 & 68,6 & 1,00 & 0,66 & 0,90 & 0,24 & 1,46 & 0,97 & 1,31 & 0,35 \\
\hline & I "com plano". & 283 & 31,4 & 0,00 & 0,34 & 0,10 & 0,76 & 0,00 & 1,08 & 0,32 & 2,41 \\
\hline \multirow{6}{*}{$\begin{array}{l}\text { v9 atividade de } \\
\text { trabalho e estudo }\end{array}$} & o "só estuda" & 29 & 3,2 & 0,00 & 0,10 & 0,00 & 0,01 & 0,00 & 3,00 & 0,00 & 0,38 \\
\hline & I "est. e trab. c/ renda" & 61 & 6,8 & 0,00 & 0,17 & 0,05 & 0,03 & 0,00 & 2,45 & 0,79 & 0,43 \\
\hline & 2 "est. e trab. s/ renda" & 10 & 1,1 & 0,00 & 0,01 & 0,01 & 0,03 & 0,00 & 0,88 & 0,80 & 2,32 \\
\hline & 3 "só trab. c/ renda" & 405 & 44,9 & 0,19 & 0,42 & 0,62 & 0,64 & 0,43 & 0,92 & 1,37 & 1,41 \\
\hline & 4 "só trab. s/ renda" & 97 & 10,8 & 0,34 & 0,00 & 0,01 & 0,07 & 3,12 & 0,00 & 0,11 & 0,63 \\
\hline & 5 "não trab. nem est.". & 300 & 33,3 & 0,47 & 0,31 & 0,31 & 0,23 & 1,41 & 0,94 & 0,93 & 0,69 \\
\hline \multirow{6}{*}{ vio primeiro método } & o "nunca usou método" & 48 & 5,3 & 0,00 & 0,00 & 0,29 & 0,00 & 0,00 & 0,00 & 5,40 & 0,00 \\
\hline & I "pílula" & 496 & 55,0 & 0,69 & 0,26 & 0,60 & 0,75 & 1,25 & 0,47 & 1,09 & 1,36 \\
\hline & 2 "camisinhas" & 150 & 16,6 & 0,00 & 0,52 & 0,00 & 0,00 & 0,00 & 3,14 & 0,00 & 0,00 \\
\hline & 3 "esterilização" & 49 & 5,4 & 0,22 & 0,00 & 0,00 & 0,00 & 4,01 & 0,00 & 0,00 & 0,00 \\
\hline & 4 "outros métodos" & 159 & 17,6 & 0,09 & 0,22 & 0,12 & 0,25 & 0,53 & 1,23 & 0,66 & 1,43 \\
\hline & 5 "não sabe/não respondeu". & & & & & & & & & & \\
\hline \multirow{5}{*}{$\begin{array}{l}\text { vil método usado } \\
\text { atualmente }\end{array}$} & o "não usa método" & 260 & 28,8 & 0,00 & 0,21 & 1,00 & 0,00 & 0,00 & 0,74 & 3,47 & 0,00 \\
\hline & I "pílula" & 116 & 12,9 & 0,00 & 0,33 & 0,00 & 0,00 & 0,00 & 2,56 & 0,00 & 0,00 \\
\hline & 2 "camisinhas" & 88 & 9,8 & 0,00 & 0,26 & 0,00 & 0,00 & 0,00 & 2,67 & 0,00 & 0,00 \\
\hline & 3 "esterilização" & 375 & 41,6 & 1,00 & 0,00 & 0,00 & 1,00 & 2,40 & 0,00 & 0,00 & 2,40 \\
\hline & 4 "outros métodos". & 63 & 7,0 & 0,00 & 0,20 & 0,00 & 0,00 & 0,00 & 2,80 & 0,00 & 0,00 \\
\hline \multirow{6}{*}{$\begin{array}{l}\text { v12 idade na primeira } \\
\text { relação }\end{array}$} & o "não informaram" & 8 & 0,9 & 0,02 & 0,00 & 0,02 & 0,00 & $\mathrm{I}, 97$ & 0,00 & 2,54 & 0,00 \\
\hline & । "9 a $14 "$ & 118 & 13,1 & 0,42 & 0,00 & 0,11 & 0,00 & 3,20 & 0,00 & 0,81 & 0,00 \\
\hline & 2 "15 a $19 "$ & 479 & 53,1 & 0,56 & 0,72 & 0,48 & 0,36 & 1,06 & 1,35 & 0,90 & 0,68 \\
\hline & 3 " 20 a $24 "$ & 199 & 22,1 & 0,00 & 0,19 & 0,18 & 0,48 & 0,00 & 0,87 & 0,81 & 2,16 \\
\hline & 4 "25 a $29 "$ & 72 & 8,0 & 0,00 & 0,08 & 0,13 & 0,13 & 0,00 & 0,95 & 1,58 & 1,61 \\
\hline & 5 "30 e mais". & 26 & 2,9 & 0,00 & 0,01 & 0,09 & 0,03 & 0,00 & 0,43 & 3,09 & 1,08 \\
\hline \multirow{4}{*}{$\begin{array}{l}\text { VI3 método usado na } \\
\text { primeira relação sexual }\end{array}$} & o "nenhum" & 698 & 77,4 & 1,00 & 0,53 & 1,00 & 0,66 & 1,29 & 0,69 & 1,29 & 0,85 \\
\hline & I "camisinha masculina" & 90 & 10,0 & 0,00 & 0,34 & 0,00 & 0,00 & 0,00 & 3,39 & 0,00 & 0,00 \\
\hline & 2 "outros métodos" & 113 & 12,5 & 0,00 & 0,13 & 0,00 & 0,34 & 0,00 & 1,03 & 0,00 & 2,71 \\
\hline & 3 "não sabe/não respondeu". & 1 & 0,1 & 0,00 & 0,00 & 0,00 & 0,00 & 0,00 & 0,00 & 0,00 & 0,00 \\
\hline \multirow{6}{*}{$\begin{array}{l}\text { VI4 média de relações } \\
\text { sexuais por mês }\end{array}$} & o "o vezes" & 182 & 20,2 & 0,00 & 0,00 & 0,92 & 0,00 & 0,00 & 0,00 & 4,57 & 0,00 \\
\hline & I "I a 4 vezes" & 232 & 25,7 & 0,55 & 0,26 & 0,00 & 0,20 & 2,13 & 1,03 & 0,00 & 0,76 \\
\hline & 2 "5 a 8 vezes" & 198 & 22,0 & 0,22 & 0,27 & 0,00 & 0,35 & 1,00 & 1,22 & 0,00 & 1,61 \\
\hline & 3 "9 a 12 vezes" & 125 & 13,9 & 0,06 & 0,21 & 0,00 & 0,26 & 0,42 & 1,48 & 0,00 & ।,86 \\
\hline & 4 "13 e mais vezes" & 131 & 14,5 & 0,17 & 0,23 & 0,00 & 0,13 & 1,20 & 1,61 & 0,00 & 0,93 \\
\hline & 5 "não sabe/não respondeu". & 34 & 3,8 & 0,00 & 0,03 & 0,08 & 0,06 & 0,00 & 0,77 & 2,01 & 1,47 \\
\hline
\end{tabular}




\begin{tabular}{|c|c|c|c|c|c|c|c|c|c|c|c|}
\hline Vari & ategorias & $\mathrm{N}$ & $\mathrm{F}$ & $\mathrm{PI}$ & $\mathrm{P}_{2}$ & $P_{3}$ & $\mathrm{P}_{4}$ & $\mathrm{PI} / \mathrm{F}$ & $\mathrm{P}_{2} / \mathrm{F}$ & $P_{3} / F$ & $\mathrm{P}_{4} / \mathrm{F}$ \\
\hline \multirow{3}{*}{$\begin{array}{l}\text { VI5 número de } \\
\text { parceiros sexuais dos } \\
\text { últimos } 12 \text { meses }\end{array}$} & "nenhum" & 140 & 15,5 & 0,00 & 0,00 & 0,87 & 0,00 & 0,00 & 0,00 & 5,61 & 0,00 \\
\hline & I "um" & 709 & 78,6 & 1,00 & 0,89 & 0,00 & 1,00 & 1,27 & 1,13 & 0,00 & 1,27 \\
\hline & 2 "dois ou mais" & 53 & 5,9 & 0,00 & 0,11 & 0,13 & 0,00 & 0,00 & 1,89 & 2,20 & 0,00 \\
\hline \multirow{4}{*}{$\begin{array}{l}\text { vi6 tipo de relação } \\
\text { com o último } \\
\text { parceiro sexual dos } \\
\text { últimos } 12 \text { meses }\end{array}$} & o "não teve sexo nos últ. 12 meses" & 140 & 15,5 & 0,00 & 0,00 & 0,76 & 0,00 & 0,00 & 0,00 & 4,88 & 0,00 \\
\hline & I "parceiro estável" & 716 & 79,4 & 1,00 & 1,00 & 0,00 & 1,00 & 1,26 & 1,26 & 0,00 & 1,26 \\
\hline & 2 "parceiro ocasional" & 43 & 4,8 & 0,00 & 0,00 & 0,24 & 0,00 & 0,00 & 0,00 & 5,07 & 0,00 \\
\hline & 3 "não sabe/não respondeu". & 3 & 0,3 & 0,00 & 0,00 & 0,00 & 0,00 & 0,00 & 0,00 & 0,00 & 0,00 \\
\hline \multirow{5}{*}{$\begin{array}{l}\text { vi7 poder para parar } \\
\text { relação sexual com } \\
\text { último parceiro } \\
\text { sexual }\end{array}$} & o "Não tentaria evitar" & 107 & 11,9 & 0,37 & 0,00 & 0,11 & 0,00 & 3,11 & 0,00 & 0,95 & 0,00 \\
\hline & I "Tentaria, mas não conseg. evitar" & 73 & 8,1 & 0,27 & 0,00 & 0,06 & 0,00 & 3,30 & 0,00 & 0,74 & 0,00 \\
\hline & 2 "Com alg. certeza conseg. evitar" & 38 & 4,2 & 0,06 & 0,04 & 0,04 & 0,03 & 1,32 & 1,03 & 0,92 & 0,71 \\
\hline & 3 "Com certeza conseguiria evitar" & 681 & 75,5 & 0,31 & 0,96 & 0,77 & 0,97 & 0,41 & I, 27 & 1,02 & 1,28 \\
\hline & 4 "não sabe/não respondeu". & 3 & 0,3 & 0,00 & 0,00 & 0,02 & 0,00 & 0,00 & 0,00 & 5,77 & 0,00 \\
\hline \multirow{5}{*}{$\begin{array}{l}\text { vi8 poder de evitar } \\
\text { relação caso parceiro } \\
\text { não queira usar } \\
\text { condom }\end{array}$} & o "Não tentaria evitar" & 212 & 23,5 & 0,77 & 0,00 & 0,00 & 0,00 & 3,30 & 0,00 & 0,00 & 0,00 \\
\hline & I "Com alg. certeza conseg. evitar" & 122 & 13,5 & 0,05 & 0,15 & 0,15 & 0,19 & 0,37 & 1,10 & 1,15 & 1,44 \\
\hline & 2 "Com certeza conseguiria evitar" & 553 & 61,3 & 0,18 & 0,84 & 0,79 & 0,79 & 0,29 & 1,37 & 1,29 & 1,29 \\
\hline & 3 "HSM" & 3 & 0,3 & 0,00 & 0,01 & 0,00 & 0,00 & 0,00 & 3,40 & 0,00 & 0,00 \\
\hline & 4 "Não sabe/não respondeu". & 12 & 1,3 & 0,00 & 0,00 & 0,05 & 0,01 & 0,00 & 0,00 & 4,05 & 1,02 \\
\hline \multirow{3}{*}{$\begin{array}{l}\text { VI9 se teve ou não IST } \\
\text { ou sintoma }\end{array}$} & o "não teve nos últ. 12 meses" & 492 & 54,5 & 0,63 & 41 & 0,76 & 0,46 & 1,16 &, 76 & 1,40 & 0,85 \\
\hline & I "teve, não fez tratamento" & III & 12,3 & 0,19 & 0,12 & 0,15 & 0,04 & 1,56 & 0,99 & $\mathrm{I}, 2 \mathrm{I}$ & 0,31 \\
\hline & 2 "teve, procurou tratamento e fez". & 299 & 33,1 & 0,18 & 0,47 & 0,09 & 0,50 & 0,53 & 1,41 &, 27 & 1,51 \\
\hline \multirow{3}{*}{ v2o aids tem cura? } & o "não tem" & 755 & 83,7 & 0,52 & 0,95 & 0,87 & 1,00 & 0,62 & 1,13 & 1,04 & 1,19 \\
\hline & I "tem" & 93 & 10,3 & 0,34 & 0,05 & 0,00 & 0,00 & 3,34 & 0,51 & 0,00 & 0,00 \\
\hline & 2 "não sabe/não respondeu". & 54 & 6,0 & 0,14 & 0,00 & 0,13 & 0,00 & 2,34 & 0,00 & 2,14 & 0,00 \\
\hline \multirow{5}{*}{$\begin{array}{l}\text { V2I autopercepção } \\
\text { de risco }\end{array}$} & o "não corre risco" & 431 & 47,8 & 0,82 & 0,30 & 0,78 & 0,16 & 1,72 & 0,62 & 1,64 & 0,33 \\
\hline & I "risco pequeno" & 268 & 29,7 & 0,00 & 0,45 & 0,04 & 0,57 & 0,00 & 1,53 & 0,15 & 1,91 \\
\hline & 2 "risco moderado" & 126 & 14,0 & 0,06 & 0,19 & 0,05 & 0,22 & 0,44 & 1,36 & 0,38 & 1,55 \\
\hline & 3 "risco grande" & 75 & 8,3 & 0,11 & 0,06 & 0,12 & 0,06 & 1,31 & 0,70 & 1,43 & 0,74 \\
\hline & 4 "não sabe/não respon & 2 & 0,2 & OI & 0,00 & 0,00 & 0,00 & 4,10 & 0,00 & 0,00 & 0,00 \\
\hline \multirow{4}{*}{$\begin{array}{l}\text { V22 se fez exame de } \\
\text { HIV quando fez }\end{array}$} & o "nunca fez" & 662 & 4 & 99 & 39 & 0,95 & 4 & 5 & 54 & 1,30 & , OI \\
\hline & I "fez há menos de I ano" & 103 & 11,4 &, 00 & 0,27 & 0,00 & 0,12 & 0,00 & 2,33 & 0,00 & 1,07 \\
\hline & 2 "fez há mais de I ano" & 129 & 14,3 & 0,00 & 0,33 & 0,05 & 0,12 & 0,00 & 2,31 & 0,32 & 0,83 \\
\hline & 3 "não sabe/não respondeu". & 8 & 0,9 & 0,01 & 0,01 & 0,00 & 0,01 & 0,81 & 1,13 & 0,00 & 1,66 \\
\hline \multirow{5}{*}{$\begin{array}{l}\text { V24 teste de HIV em } \\
\text { pré-natal } \\
\text { (nascimentos até } \\
5 \text { anos antes da } \\
\text { pesquisa) }\end{array}$} & I "filho nos últ. 5 anos s/ teste" & 143 & 15,9 & 0,22 & 0,27 & 0,00 & 0,06 & $\mathrm{I}, 37$ & I,68 & 0,00 & 0,38 \\
\hline & 2 "filho nos últ. 5 anos c/ teste" & 80 & 8,9 & 0,00 & 0,27 & 0,00 & 0,00 & 0,00 & 2,99 & 0,00 & 0,00 \\
\hline & 3 "nunca teve filho" & 163 & 18,1 & $0, \infty$ & 0,43 & 17 & 0,00 & 0,00 & 2,36 & 0,92 & 0,00 \\
\hline & 4 "grávida pela primeira vez" & II & 1,2 & 0,00 & 0,04 & 0,00 & 0,00 & 0,00 & 3,29 & 0,00 & 0,00 \\
\hline & 5 "teve filho há mais de 5 anos". & 505 & 56,0 & 0,78 & 0,00 & 0,83 & 0,94 & 1,40 & 0,00 & 1,49 & 1,68 \\
\hline \multirow{5}{*}{$\begin{array}{l}\text { V23 participação } \\
\text { do parceiro sobre a } \\
\text { decisão do uso de } \\
\text { método }\end{array}$} & o "só entrevistada" & 98 & 10,9 & 0,00 & 0,33 & 0,00 & 0,00 & 0,00 & 3,06 & 0,00 & 0,00 \\
\hline & I "só o marido ou comp." & 8 & 0,9 & 0,01 & 0,02 & 0,00 & 0,00 & 0,78 & 2,64 & 0,00 & 0,00 \\
\hline & 2 "por ambos" & 199 & 22,1 & 0,00 & 0,64 & 0,00 & 0,00 & 0,00 & 2,91 & 0,00 & 0,00 \\
\hline & 3 "esterilizadas/sem parceiro fixo" & 522 & 57,9 & 0,99 & 0,00 & 0,64 & 1,00 & 1,72 & 0,00 & 1,10 & $\mathrm{I}, 73$ \\
\hline & 4 "não sabe/não respondeu". & 75 & 8,3 & 0,00 & 0,00 & 0,36 & 0,00 & 0,00 & 0,00 & 4,39 & 0,00 \\
\hline
\end{tabular}

Fonte dos dados básicos: Pesquisa Saúde Reprodutiva, Sexualidade e Raça, 2002. 


\section{Considerações Finais}

Neste trabalho, procurou-se delinear os perfis de mulheres brancas e negras, entre 18 e 59 anos em Belo Horizonte e Recife, utilizando-se características sociodemográficas e de conhecimento e atitudes em relação ao HIV/aids. Embora aspectos relativos a conhecimento e atitudes não sejam tão simples de serem tratados quanto variáveis de natureza sociodemográfica, eles trazem informações de grande valor para ampliar o entendimento da vulnerabilidade ao HIV/aids, uma vez que revelam pontos que, associados com outros, tornam os indivíduos menos capazes de controlar seu risco à infecção e, consequentemente, mais vulneráveis à infecção e à doença.

Os resultados aqui apresentados reforçam o conceito de vulnerabilidade preconizado pela UNAIDS, segundo o qual pobreza e desigualdade de gênero, além de outros fatores, podem ampliar a vulnerabilidade dos indivíduos ao HIV e, portanto, precisam ser abordados nas ações desenvolvidas para combater os avanços da epidemia. Tanto em Belo Horizonte quanto em Recife, as mulheres com níveis mais baixos de escolaridade e fora do mercado de trabalho são as que apresentaram maior probabilidade de acreditarem que a aids tem cura ou de não saberem se tem cura. Também são elas que apresentam probabilidades mais elevadas de acharem que não têm risco de contrair a infecção. Nesse sentido, enfrentar questões relativas à escolaridade das mulheres é imperativo para o enfrentamento do problema. Para isso, é preciso romper com o legado discriminatório que permeia a história de nosso país e que expõe as mulheres negras a situações de vulnerabilidade mais elevadas. No balanço geral, são elas as que têm menor acesso à escola e possibilidades mais limitadas no mercado de trabalho.

O quadro de desigualdade nas relações de gênero é outro aspecto que também chama atenção nos resultados aqui apresentados. Em geral, as mulheres ainda têm muita dificuldade para negociar com o parceiro o uso do preservativo durante as relações sexuais. Esse cenário fica ainda mais preocupante quando o que se constata é que a probabilidade de sexo seguro diminui dentro das relações estáveis e entre as mulheres de grupos etários mais avançados. Esse cenário foi constatado tanto em Belo Horizonte quanto em Recife (perfis 1 e 4, respectivamente). A promoção da igualdade de gênero é uma tarefa árdua, mas que precisa também ser enfrentada se há um desejo firme de se cruzar obstáculos significativos na prevenção ao HIV/aids.

No que se diz respeito à raça/cor, as brancas estão sempre associadas aos perfis de melhor situação socioeconômica em ambos os municípios. Tanto em Belo Horizonte quanto em Recife, as mulheres com maior probabilidade de serem brancas são também aquelas com maior probabilidade de ter escolaridade mais elevada, possuir plano de saúde, ter tido parceiro estável no ano anterior à pesquisa e ter poder na relação sexual. Quanto às negras, apenas em Belo Horizonte essa variável é significante e faz parte das características do perfil de mais baixo nível socioeconômico. Assim, as mulheres com maior probabilidade de serem negras em Belo Horizonte também são aquelas com maior probabilidade de terem baixa escolaridade, não possuírem plano de saúde e não terem poder de negociação diante do parceiro sexual.

Esses resultados revelam que, mesmo com todos os avanços sociais e econômicos que permeiam o país, velhas questões ainda precisam ser resolvidas se quisermos romper com o legado discriminatório que impede que uma parcela expressiva da população tenha acesso a melhores condições de vida.

\section{Referências}

ANTUNES, M. C. et al. Diferenças na prevenção da aids entre homens e mulheres jovens de escolas públicas em São Paulo, SP. Revista de Saúde Pública, São Paulo, v. 36, n. 4, supl., aug. 2002.

ALVES, L. C.; LEITE, I. C.; MACHADO, C. J. Perfis de saúde de idosos no Brasil: análise da Pesquisa Nacional por Amostra de Domicílios 2003 utilizando o método Grade of Membership. Cadernos de Saúde Pública, Rio de Janeiro, v. 24, n. 3, p. 535-546, 2008. 
BARBOSA, L. M. Perfis de vulnerabilidade ao risco de contrair o HIV nas regiões Nordeste e Sudeste brasileiras: aspectos individuais e da comunidade. 2001. 158f. Tese (Doutorado em Demografia) - Centro de Desenvolvimento e Planejamento Regional, Universidade Federal de Minas Gerais, Belo Horizonte, 2001.

BASTOS, F. I.; SZWARCWALD, C. L. Aids e pauperização: principais conceitos e evidencias empíricas. Cadernos de Saúde Pública, Rio de Janeiro, v. 16, supl. 1, 2000.

BONOLO, P. F. et al. Vulnerability and nonadherence to antiretroviral therapy among HIV patients, Minas Gerais State, Brazil. Cadernos de Saúde Pública, Rio de Janeiro, v. 24, n. 11, p. 26032613, 2008.

BRASIL. Ministério da Saúde. Secretaria de Vigilância em Saúde. Programa Nacional de DST e Aids. Boletim Epidemiológico Aids, ano IV, n. 1, Brasília, 2007.

BRASIL. Ministério da Saúde. Secretaria de Vigilância em Saúde. Programa Nacional. Boletim Epidemiológico-Aids, Brasília, ano III n. 1 - 1ª a $26^{\text {a }}$ semanas epidemiológicas, jan.-jun. 2006.

CAETANO, A. J.; MACHADO, C. J. Consistência e identificabilidade no modelo Grade of Membership: uma nota metodológica. Revista Brasileira de Estudos de População, São Paulo, v. 26, n. 1, p.145-149, 2009.

CARVALHO, J.A.M.; WOOD, C. H.; ANDRADE, F.C.D. Estimating the stability of census based racial/ ethnic classifications: The case of Brazil. Population Studies, London, v. 58, n. 3, p. 331-343, 2004.

DINIZ, S. G. Gênero e prevenção das DST/aids. Coletivo Feminista Sexualidade e Saúde. São Paulo, [s.d.].

FINKLER, L.; BRAGA, P.; GOMES, W. B.

Percepções de casais heterossexuais em relação à suscetibilidade de infecção por HIV/aids. Interação em psicologia, v. 8, n. 1, p. 113-122, 2004. FONSECA, M. G. P.; BASTOS, F. I. Twenty-five years of the AIDS epidemic in Brazil: principal epidemiological findings, 1980-2005. Cadernos de Saúde Pública, Rio de Janeiro, n. 23 supl. 3, 2007.
GUIMARÃES, A. S. A. Como trabalhar com "raça" em sociologia. Educação e Pesquisa, São Paulo, v. 29, n. 1, p.93-108, 2003.

INSITUTO BRASILEIRO DE GEOGRAFIA E ESTATÍSTICA - IBGE. Censo Demográfico de 2ooo: microdados. Rio de Janeiro: IBGE, 2002.

LOPES, F. Mulheres negras e não negras vivendo com HIV/aids no estado de São Paulo: um estudo sobre suas vulnerabilidades. 2003. 203f. Tese (Doutorado em Saúde Pública) - Departamento de Epidemiologia da Faculdade de Saúde Pública, Universidade de São Paulo, São Paulo, 2003.

MANN, J.; TARANTOLA, D. J. M.; NETTER, T. W. (Ed.). AIDS in the world. Cambridge: Harvard University Press, 1992. 1037 p.

MANTON, K. G.; WOODBURY, M. A.; TOLLEY, H. D. Statistical applications using fuzzy sets. New York: John Wiley, 1994. $312 \mathrm{p}$.

MIRANDA-RIBEIRO, P.; CAETANO, A. J.; SANTOS, T. F. SRSR - Saúde reprodutiva, sexualidade e raça/cor: relatório descritivo. Belo Horizonte: UFMG; Cedeplar, 2004.36 p.

MIRANDA-RIBEIRO, P. et al. Acesso à contracepção e ao diagnóstico do câncer de colo uterino em Belo Horizonte: uma contribuição metodológica aos estudos quanti-quali. Revista Brasileira de Estudos de População, São Paulo, v. 24, n. 2, p. 341-344, 2007.

MIRANDA-RIBEIRO, P. et al .É igual chupar bala com papel: a vulnerabilidade feminina ao HIV/ aids e o uso de camisinha em Belo Horizonte e Recife. In: MIRANDA-RIBEIRO, P.; SIMÃO, A. B. (Org.). Qualificando os números: estudos sobre saúde sexual e reprodutiva no Brasil. 2. ed. Belo Horizonte: ABEP; UNFPA, 2009, p. 391-416.

OLINTO, M. T. A.; GALVAO, L. W. Características reprodutivas de mulheres de 15 a 49 anos: estudos comparativos e planejamento de ações. Revista de Saúde Pública, São Paulo, v. 33, n. 1, p. 64-72, 1999. Disponível em: <http://www.scielosp.org/scielo. php?script=sci_arttext\&pid=Soo34-891019990o o100009\&lng=en\&nrm=isso>. Acesso em: 20 jan. 2007. 
OLINTO, M. T. A; OLINTO, B. A. Raça e

desigualdade entre as mulheres: um exemplo no sul do Brasil. Cadernos de Saúde Pública, Rio de Janeiro, v. 4, n. 16, p. 1137-1142, 2000.

PAIVA, V. et al. A vulnerabilidade das mulheres ao HIV é maior por causa dos condicionantes de gênero? Cuadernos Mujer y Salud, Santiago, v. 3 , p. 34-38, 1998.

SANTELLI, J. S. et al. Stage of behavioral change for condom use: the influences of partner type, relationship and pregnancy factors. Family Planning Perspectives, New York, v. 28, n. 3, p. 101107, may-june 1996.

SANTELLI, J. S. et al. Multiple sexual partners among US adolescents and young adults. Family Planning Perspectives, New York, v. 3o, n. 6, p.271275, nov.-dec. 1998.

SANTOS, C. O.; IRIART, J. A. B. Significados e práticas associadas ao risco de contrair HIV nos roteiros sexuais de mulheres de um bairro popular de Salvador, Bahia, Brasil. Cadernos de Saúde Pública, Rio de Janeiro, v. 23, n. 12, dez. 2007.

SAWYER, D. O.; LEITE, I. C.; ALEXANDRINO, R. Perfis de utilização de serviços de saúde no Brasil. Ciência \& Saúde Coletiva, Rio de Janeiro, v. 7, n. 4, p. 757-76, 2002.
SILVA, N. V. Uma nota sobre "raça social" no Brasil. In: HASENBALG, C.; SILVA, N. V.; LIMA, M. (Org.). Cor e estratificação social. Rio de Janeiro: Contra Capa Editora, 1999, p.107-125.

TORRES, M. E. A.; MIRANDA-RIBEIRO, P.; MACHADO. C. J. "Vai lá, tira a roupa... e... pronto...”: o acesso a consultas ginecológicas em Belo Horizonte, MG. Revista Brasileira de Estudos de População, São Paulo, v. 25, n. 1, p. 49-69, jan.-jun. 2008.

TELLES, E. E. Racismo à brasileira: uma nova perspectiva sociológica. Rio de Janeiro: Relume Dumará, 2003. 347 p.

UNAIDS. The UNAIDS Report. Geneva: UNAIDS, 1998. Disponível em: <http://data.unaids.org/ publications/IRC-pubo1/jc2o8-corpreport_en.pdf >. Acesso em: 20 jan. 2007.

VILLELA, W. Dossiê Mulher e Aids. São Paulo: Rede Feminista de Saúde, 2001. Disponível em: <https://sistema.planalto.gov.br/ spmulheres/biblioteca_consulta_ficha.cfm?cd item=28166 $>$ Acesso em: 20 jan. 2007. 